\title{
Chile actual: el proyecto político de la Concertación
}

\author{
CARLOS PEÑA GONZALEZ ${ }^{1}$ \\ Universidad Diego Portales
}

\begin{abstract}
Resumen
El texto que sigue examina la situación actual del proyecto de la Concertación de Partidos por la Democracia y los desafíos a los que deberá hacer frente. Haciendo pie en un texto de Marx, sugiere que los gobiernos de la Concertación han empujado un extendido proceso de modernización cuyas consecuencias, sin embargo, la coalición de gobierno es incapaz de narrar. La Concertación ha hecho la historia en los últimos veinte años; pero no supo la historia que hacía. Como consecuencia del cambio en las condiciones materiales de la existencia, se produjeron cambios culturales en una multitud de dimensiones de la vida colectiva que es necesario ahora gestionar. Esos cambios van desde el deterioro de las formas comunitarias, al nuevo equilibrio entre la política democrática y el policy making.
\end{abstract}

Palabras clave: Ideología - Modernización - Política Democrática - Individuación.

\begin{abstract}
This paper examines the current stage of the project of the Concertación de Partidos por la Democracia and the challenges that it has to face. Following a text of Marx, it suggests that the governments of the Concertación have promoted an extensive process of modernization whose consequences, however, the official coalition is unable to interpret. The Concertación has made the history of the last twenty years but it did not know the history that made. As a consequence of the change in the material conditions of the existence, it has taken place cultural transformations in numerous dimensions of the collective life that are now necessary to deal with. These changes range from the weakening of the communitarian forms to the new equilibrium between democratic politics and policy making.
\end{abstract}

Key Words: Ideology - Modernization - Democratic Politics -Individuation.

\footnotetext{
Rector Universidad Diego Portales. Abogado con estudios de postgrado en Sociología (PUC) y Filosofia (U de Chile)
} 
¿Cuál es el presente y cuál el futuro de la Concertación de Partidos por la Democracia? ¿Es verdad -como se ha sugerido (vid. Moulian, 2006; Correa, 2004: 284; Peña, 2007)- que acabó realizando el proyecto de modernización de la derecha y que por lo mismo carece ya de sentido histórico? ¿En qué sentido, si es que en alguno, es ideológico ese proyecto?

Para responder esas preguntas quizá sea útil comenzar con una reflexión que Marx escribió en una obrita de juventud: el Dieciocho Brumario de Luis Bonaparte. En ese texto -escrito en medio del fragor de las luchas de mediados del diecinueve, como un análisis de la segunda república francesa que terminó una vez que el sobrino de Napoléon dió un golpe de estado- Marx dice que los hombres hacen su historia, pero no la hacen bajo condiciones elegidas por ellos mismos, sino bajo condiciones directamente existentes, dadas y heredadas. "La tradición de todas las generaciones muertas, dice Marx, continúa en el presente gravitando sobre el cerebro de los vivos" (Marx, 2003:33). Esa misma frase fue la que inspiró más tarde otra levemente distinta que aparece en la correspondencia de Engels: los hombres hacen su historia pero no saben la historia que hacen (Marx y Engels, 1972: 394)

Esos textos sugieren que la acción política es una mezcla de voluntad y de fatalidad: la voluntad que tenemos ha de desenvolverse en medio de circunstancias que no dependen de ella, que simplemente nos vienen dadas y que, nos guste o no, ya se configuraron. La otra frase es una consecuencia de eso: hacemos la historia, pero justamente porque no dominamos a nuestro antojo las circunstancias en medio de las que ella se produce, no sabemos la historia que hacemos.

Todo proyecto político estaría, en suma, amenazado alguna vez por la ceguera. Como en la mirada de paralaje que sugiere Žižek (Žižek, 2006: 26) en todo proyecto político habría un punto ciego que consistiría en la imposibilidad de mirar el propio punto de vista. Las condiciones heredadas de que habla Marx hacen posible un proyecto; pero al mismo tiempo impiden considerar su contingencia. Así, el juego entre lo visible (los resultados) y lo invisible (las condiciones heredadas), que es propio de toda ideología, comparece en la política (Žižek, 2005: 7)

Sobre el fondo de esa sencilla constatación - a saber, que todo proyecto político acaba en un punto ciego- las notas que siguen intentan caracterizar el actual momento que vive la Concertación de Partidos por la Democracia a fin de dilucidar si es posible revalidar ese proyecto político haciendo frente a las nuevas circunstancias. De lo que se trata, en suma, es de preguntarse cuáles son los problemas - pero también los desafios- que ese proyecto político tiene por delante.

Ahora bien, si Marx tiene razón, y yo pienso que la tiene, al analizar las condiciones presentes de la Concertación y sus perspectivas de futuro debemos, ante todo, dilucidar cuáles son esas condiciones que no hemos elegido, esas condiciones heredadas, 
en medio de las cuales cualquier proyecto político, como el de la Concertación, pero lo mismo vale para la derecha, debe desenvolverse hoy día.

Preguntémonos entonces ¿Qué es lo que ha ocurrido en los últimos veinte años y qué es lo que previsiblemente la acción política podría hacer que ocurriera en los años venideros? Si logramos identificar lo que ha ocurrido en estos años-esas condiciones heredadas, como dice Marx- me parece que habremos dado un paso para comprender qué es lo que una coalición de centroizquierda como la de la Concertación debe hacer por delante. Para decirlo en una palabra, lo que pienso es que la Concertación está siendo víctima de su propio éxito. No supo la historia que hacía y hoy día arriesga el peligro de ser incapaz de narrar su propio éxito.

En otras palabras, pienso que el problema de la Concertación es que la historia que ella misma hizo o contribuyó a hacer va más rápido de lo que sus dirigentes, que miran hacia atrás una y otra vez en busca de legitimidad, son capaces de comprender.

Permítanme revisar los hechos de estos últimos veinte años y observar esas consecuencias que, como digo, van por delante de nuestras estructuras políticas.

El hecho más notorio de los últimos veinte años es el cambio en las condiciones materiales de la existencia de los chilenos. Nunca, como hoy, las mayorías habían estado mejor. La educación básica y media se ha expandido, hoy día la cobertura es casi universal y las expectativas de escolaridad para un niño de 5 años es hoy de 15, 6 años apenas una fracción por debajo de los países de la OECD; la educación superior se ha masificado y ya traspasamos el $40 \%$ de cobertura y siete de cada diez alumnos son hijos de padres que nunca alcanzaron ese nivel educacional (Brunner y Peña, 2007); la vivienda propia, antes una verdadera quimera, hoy día es una realidad para el 75\% de los chilenos; el automóvil se ha masificado y los medios de comunicación se han expandido como nunca antes; los malls proliferan y el consumo de bienes materiales y de bienes simbólicos, se hincha (Tironi, 2003: 31-40). En suma, somos hoy día más prósperos y la miseria, afortundamente, cada día se achica y se arrincona. Los chilenos vivimos hoy día más y vivimos mejor y nunca antes en la historia las grandes mayorías habían experimentado en el curso de quince o veinte años cambios que antes se alcanzaban en dos o tres generaciones. En otras palabras, nunca la biografia personal de tantos hombres y mujeres fue capaz de recoger en el curso de su propia vida cambios tan bruscos y tan radicales, y por eso hoy día las mayorías se han vuelto más insumisas e infieles y no es tan dificil explicar por qué eso ha ocurrido: cuando usted ha experimentado en el curso de una década y media que su vida puede cambiar tan radicalmente, ya no cree en los relatos ideológicos que le enseñaban a esperar y a comportarse bien. Las mayorías, en una palabra, ya no comulgan con ruedas de carreta.

Ese cambio en las condiciones materiales de la existencia - uno de los más grandes éxitos de los gobiernos de la Concertación- ha provocado, por su parte, un conjunto 
de cambios culturales, un conjunto de transformaciones en la esfera de la subjetividad de los chilenos.

Desde luego, el cambio en las condiciones de vida de las mayorías y la expansión del consumo que, a pesar de todas las desigualdades, experimentan, provoca reacciones encontradas en las elites que se ven hasta cierto punto desplazadas por esos procesos. Esos grupos sociales que dejaron de ser proletarios en el sentido de los años sesenta, para pasar a ser grupos aspiracionales que migran dentro de la ciudad en busca de un destino mejor, no son comprendidas del todo por las elites que ven en el avance de estos procesos el imperio de la vulgaridad y de la ordinariez, un simple peligro de chabacanería o de alienación. En esto las élites de izquierda y de derecha se parecen: unas y otras ariscan la nariz frente a la expansión del consumo y del mercado. Las elites se quejan de la tele, de los diarios, de la juventud, de las tribus urbanas, de los grafittis, de los rumores y de los cambios en la afectividad religiosa. Parecen creer que es posible aumentar el consumo y aumentar el bienestar material de la gente sin que ella experimente profundos cambios en su manera de ver y estar en el mundo. La literatura y la evidencia empírica muestran sin embargo, que no se requiere ser marxista para darse cuenta que el cambio en las condiciones materiales de la existencia humana va siempre acompañado de cambios espirituales, de cambios en la manera en que nos vemos a nosotros mismos y vemos a los demás.

Esos cambios culturales que menciono se extienden desde los cambios en la intimidad a los cambios en la esfera pública.

\section{La dimensión íntima de la existencia también busca reconocimiento.}

Unas chicas besándose en la portada del diario de mayor circulación en Chile; una jueza lesbiana que porfía por tener cerca a sus hijos; personajes públicos que salen del clóset; estudiantes gays que se organizan y reclaman sus derechos; teleseries que compiten por erotizar el trasnoche; crónicas que relatan los primeros divorcios como si fueran comedias; la diversidad de las formas de vida familiar; el deseo de vivir en familia y sentir al mismo tiempo que ella es cada vez más frágil; y el culto sin freno a la sinceridad en entrevistas y en diálogos, son, todos, síntomas de los cambios que la sociedad chilena experimenta en la esfera de la intimidad, ese ámbito, apenas ayer, cercado por el pudor y por el sigilo (vid. Peña, 2006: 35-43)

Pero no sólo ha habido cambios en la intimidad. La esfera pública también se ha transformado radicalmente y la mejor muestra de eso son los cambios en los medios de comunicación.

Los medios de comunicación fueron concebidos históricamente como espacios de ilustración de las mayorías por parte de las elites culturales, políticas y religiosas, tanto 
en el siglo XIX como en el siglo XX. La mejor muestra de esto es el modelo de televisión chileno a cargo de las Universidades. Pues bien, hoy día los medios son un espacio abierto y sensible a las audiencias y en el que en vez de ilustrarse a las mayorías y a las audiencias, se les entretiene, se les aligera la vida y, de paso, se somete a escrutinio y se desconfia de las elites de toda índole. ¿Cómo explicar de otra manera la cantidad de escándalos que comparecieron en la esfera pública nada más en los últimos cinco años, escándalos que cuando estos cambios culturales todavía no se producían, nadie se hubiera atrevido siquiera a mencionar? En los años que recién pasaron, hubo no sólo escándalos políticos o económicos, hubo todavía otros que dejaron a clérigos a la altura de personajes de Bocaccio, a empresarios como abusadores o rapaces, a senadores con su prestigio magullado casi para siempre, a militares como scouts torpes, a un ministro como un adolescente voyerista e inexperto y a una jueza como una bribona. Todo eso proviene de la debilidad de las elites y del hecho que el prestigio en Chile se está redistribuyendo y nuevas hegemonías culturales están, con toda seguridad, apareciendo poco a poco (vid. Thompson, 1998, 1990, 2001)

Todos esos procesos que acabo de dibujar someramente, no son anomalías, no son patologías: son un fruto del éxito que han tenido los gobiernos de la Concertación en estimular y desatar procesos de modernización que, si sacamos bien las cuentas, han hecho de esta vida, algo mejor para todos.

Lo que yo observo está ocurriendo hoy es que la Concertación se muestra desorientada frente a esos procesos, frente a esos cambios sociales y culturales que son, insisto, consecuencia de su propio éxito. La Concertación, como diría Marx, hizo la historia de todos estos años; pero no sabía la historia que hacía y ahora al darse cuenta -al mirar las transformaciones que acabo de relatar- se paralogiza, se desbanda y se desordena.

Pero no hay motivo alguno para el desconcierto. Para volver de nuevo sobre Marx, los genuinos cambios sociales requieren mirar al futuro.

Desatada la modernización, ahora es necesario ocuparse de orientar normativamente esos procesos.

Permítanme nada más dibujar los aspectos más gruesos que nos depara el fufuro para mostrar de que forma existe allí un ámbito de asuntos que podrían configurar el nuevo guión histórico de la Concertación de Partidos por la Democracia.

En primer lugar, y como resultado de los procesos que denantes relaté, hay hoy día en Chile un dilema entre individualismo y comunidad. Pareciera que conforme los individuos se sienten más orgullosos de sí mismos y ganan en autonomía, se produce al mismo tiempo un déficit de integración social. Es este un proceso que ha sido des- 
crito ampliamente por la literatura sociológica desde sus mismo orígenes. En todas partes la modernización es vista como una pérdida de arraigo de las formas de vida más tradicionales, en especial por la pérdida de esas formas de vida que responden al tipo de la comunidad.

¿Es posible, sin embargo, debemos preguntarnos, compatibilizar la autonomía y la individuación que es propia de la expansión del mercado y del consumo con un cierto sentido de equipo, con ciertas virtudes solidarias y con la convicción que vivimos en medio de una empresa colectiva? ¿Es posible, en otras palabras, compatibilizar individuación con comunidad? Las viejas pertenencias que conferían seguridad -la clase social, la iglesia, la nación- y los relatos culturales que nos sostenían y alimentaban la esperanza colectiva -las ideologías y las creencias- se han debilitado y es probable que uno de nuestros desafios consista en generar espacios de encuentro en el que todos nos podamos reconocer como iguales. Una sociedad democrática vigorosa y atenta, necesita desarrollar en sus miembros la idea que se trata de una empresa común, que compromete a todos los contemporáneos, pero en la que también los que ya se fueron pusieron su parte y en la que los que vendrán pondrán la suya. Ese tipo de compromiso cívico sobre el que se soporta la democracia, requiere que los miembros de la sociedad se sientan vinculados con las demás personas que forman parte de su comunidad. La educación y la industria cultural, las escuelas, las universidades, los intelectuales, tienen aquí una tarea para emprender (Cfr.Putnam, 1994, 1995, 2002)

Ahí hay entonces un primer desafio: transitar desde una coalición que aseguró las condiciones para que cada uno se sintiera más autónomo y más individuo, a una coalición que sea capaz de asignar significados a la vida que tenemos en común. Este desafio podría permitir a la Concertación vincularse con el acontecimiento de mayor simbolismo que vivirá nuestro país en este siglo: el bicentenario.

Para encarar este primer desafio es imprescindible, sin embargo, desmontar un punto de vista acerca de la sociabilidad que ha sido hegemónico en Chile en los últimos años. Ese punto de vista concibe a todas las formas sociales como remedos más o menos imperfectos del mercado; en suma, como la convergencia de preferencias puramente individuales que anteceden a la política. Este punto de vista - que acaba reduciendo la propia democracia a la suma de preferencias individuales- reduce los procesos de modernización a la expansión de los derechos individuales sin considerar, con igual énfasis, la necesidad de un soporte social que confiera sentido a esos procesos. Enfrente de esa reducción -que está a la base de las ciencias sociales, como lo muestra la disputa clásica entre Spencer y Durkheimse hace necesario compatibilizar el reclamo normativo por mayor autonomía, con el fortalecimiento desde el punto de vista público de las diversas formas asociativas - desde la familia a la escuela- que permiten a esa misma autonomía encontrar orientación (Durkheim, 2003: 286 y sgts.). Individualismo y autonomía, por su- 
puesto; a condición de no olvidar que incluso el individuo es un producto ex post social (vid. Taylor, 1995)

En segundo lugar hay en Chile una demanda de seguridad en todos los ámbitos de la vida, desde el fisico al medioambiental y al emocional. Los procesos de expansión del consumo y del bienestar que ha vivido nuestro país tienden a privatizar el riesgo. El costo de ese proceso -según lo ponen de manifiesto algunos estudios- es que los chilenos también sienten que viven un poco más a la intemperie y que el bienestar puede ser también un castillo de naipes que en cualquier momento puede desplomarse. Si antes el grito de las mayorías era jtenemos hambre!, hoy día el reclamo parece ser jtenemos miedo! (Cfr. Baumann, 2001). Hay aquí, me parece, un desafio que no se ha logrado resolver bien y que se ha considerado de manera más bien estrecha reduciendo todo a un asunto de seguridad policial.

En otras palabras, hemos instituido al delincuente, a quien infringe la ley en el símbolo de todos nuestros malestares. Sospecho, sin embargo, que las fuentes de malestar e inseguridad son superiores a esa y la tarea de la coalición debe ser interpretar esos malestares y darles acogida.

En tercer lugar tenemos el desafio de alcanzar equidad en los procedimientos para tolerar así la desigualdad de resultados. El dilema de Chile no consiste en escoger entre una sociedad de iguales o una de desiguales. El dilema de nuestro país consiste en escoger entre una sociedad de herederos donde el bienestar se distribuye en atención a la cuna, o una sociedad donde el desempeño personal configure nuestro destino. Si bien el bienestar se ha expandido, y si es cierto que hoy las mayorías viven mejor que antes, la desigualdad persiste en Chile y ha adquirido niveles moralmente intolerables. Porque ¿habrá algún otro lugar en el mundo donde, como en Chile, se cultiven, casi con el mismo esmero, las declaraciones a favor de la igualdad y la práctica de la más hiriente desigualdad? ¿Existirá otro país en el que se subraye, con tanto empeño, la importancia de la educación para el logro de la igualdad, pero, al mismo tiempo se tolere, y a pretexto de la libertad de enseñanza se aliente, un sistema escolar estructurado conscientemente por clases sociales, un sistema que no hace diferencia alguna entre la cuna y el aula y en el que las oportunidades de aprendizaje se distribuyen al compás del ingreso familiar? En materia de desigualdad somos casi tan excepcionales como en nuestros logros y nuestro país sigue siendo todavía una sociedad de herederos donde la cuna marca a fuego a los niños diciéndoles desde muy temprano qué lugar ocuparán en la escala invisible del prestigio y del poder. No se trata, por supuesto, de pretender un ideal igualitarista a ultranza, puesto que las desigualdades son inevitables y todos aspiramos a transmitir ventajas a nuestros hijos; pero todo eso plantea en Chile el desafio de contar con un sistema educacional y un mercado laboral que sea más equitativo desde el punto de vista de los procesos en base a los cuales se distribuyen las oportunidades y la riqueza. Si no todos podemos estar en el quintil más alto de ingre- 
sos, sí, en cambio, podemos ser tratados con más justicia. Para eso hay que reformar el sistema escolar. Mirar más a la escuela y menos a la universidad.

La Concertación en esta parte arriesga el peligro de despilfarrar una oportunidad histórica: la de mejorar el sistema educativo, el lugar donde se generan todas las hegemonías. Desgraciadamente estamos desaprovechando esa oportunidad y no contamos todavía con ninguna narrativa que le explique a las mayorías porqué debe confiar en que la coalición puede mejorar. La Concertación debe hacer suyo -simbólicamente- el diseño para mejorar la educación en Chile.

En cuarto lugar hay también un dilema en las organizaciones empresariales que se relaciona con la cultura del trabajo. La cultura del trabajo de la posguerra, inspirada en la Ford Company, con salario seguro, consumo ampliado, división sexual del trabajo y sindicatos fuertes, está siendo sustituida en algunos sectores por una cultura del trabajo flexible que establece compromisos con un pequeño grupo de trabajadores, entregando a los demás a subcontratistas o empresas externas. Todo esto aumenta la sensación de inseguridad; pero por sobretodo induce también una falsa sensación de modernidad en el trabajo. A fin de cuentas, el trabajo flexible para las mujeres no está acompañado en nuestro país de cambios en la división sexual del trabajo, el debilitamiento de la cultura sindical - que si bien tenía defectos, poseía también virtudes- no logra ser reemplazada por la simple gestión; las pequeñas y medianas empresas que la cultura de la flexibilidad fomenta cuando las grandes empresas exteriorizan servicios, es también una forma de hacer renacer empresas familiares que no siempre son eficientes. En fin, me parece que en el ámbito de la cultura del trabajo falta mirar con más distancia los logros del managment y de la gestión.

Este es un aspecto en el que falta mucho por hacer. El mercado del trabajo es clave para la cohesión social, el orgullo personal y la dignidad de las personas (Vid. Offe, 1997) y se requiere allí más sensibilidad de aquella que es capaz de proveer la economía neoclásica y el management en el que hasta ahora se ha confiado.

A lo anterior se suma que hay que eludir el falso dilema entre populismo y democracia eficiente. Las elites experimentan hoy día un cierto malestar con la democracia. Nos molesta que las audiencias sean infieles y le tenemos temor a los políticos mediáticos. Todo eso oculta un cierto desprecio por la cultura de masas y por eso me parece que en vez de quejarnos y esperar que las mayoría siempre escojan a los virtuosos, hay que mejorar la democracia incrementando la participación, haciendo más fluídos los canales por los que se comunican los ciudadanos con sus representantes, distribuir con mayor igualdad el capital cultural disponible, mejorar la educación vinculándola con la ciudadanía, aumentar la calidad de las encuestas (hoy día precarias) y hacer más competitiva la industria cultural. Nada se logrará suponiendo que las mayorías y las audiencias que tienen la última palabra a la hora del mercado, deban callar cuando se trata de modelar la vida en común. 
En fin, resta el dilema, ya viejo, entre la política democrática, por una parte, y el policy making, por la otra.

La política democrática supone, en un sentido típico ideal, la existencia de una comunidad que se autogobierna y que, mediante la deliberación, corrige los resultados del azar natural y de la historia. Uno de los aspectos más importantes de la política democrática, en la que están de acuerdo desde Mannheim a Žižek, pasando por Weber, es su dimensión aspiracional que impide que la línea que divide lo posible de lo imposible, lo que es contingente de lo necesario, quede fijada de una vez y para siempre naturalizando la vida social (Cfr. Mannheim, 1966; Weber, 1997; Zizek, 2005). Pues bien, enfrente de la política democrática se encuentran las políticas públicas, y su ejecutor, el policy maker, cuyo supuesto más acusado es que la vida social está sometida a leyes indóciles a la deliberación y a las que simplemente cabe inteligir para someternos a ellas (vid. Peña, 2003). Esta dimensión ideológica de las políticas públicas se ha hecho cada vez más acusada conforme se consolida el modelo de mercado, dando origen a un manejo hasta cierto punto tecnocrático de la vida en común.

Hay varios fenómenos que contribuyen a esa pérdida de la dimensión deliberativa de la democracia y el más obvio parece ser la convicción, cada vez más extendida, conforme a la cual la facticidad de los procesos sociales se nos impone a tal punto que cualquier deliberación es inútil, de manera que la política queda reducida a la astucia, a la picardía para conseguir la adhesión de las personas (que parece ser hoy la única tarea del político profesional) o identificada con la pertenencia a una simple cultura de expertos. La democracia arriesga así el peligro de transitar desde la figura del político profesional, cada vez más parecido a un encantador de serpientes, o a un pícaro, a la pericia del policy maker que, a fin de cuentas, mira al político profesional con cierto desdén, como una excrescencia necesaria, pero intelectualmente prescindible.

El precedente fenómeno (este desplazamiento de significado de la idea de deliberación y el consiguiente deterioro de las idea de lo público) está, por otra parte, acompañado de otros procesos, largamente descritos en la literatura, entre los que se cuenta la casi definitiva insubordinación del sistema económico, al extremo que el sistema político ha perdido toda posibilidad de deliberar acerca de sí mismo. Se agrega a ello ese otro proceso que ha sido llamado individuación, consistente en que el individuo pierde su referencia con los grupos primarios y pasa a quedar desprovisto de ámbitos de significado que le permitan trascenderse.

En medio de ese panorama -en el que la política ha llegado a identificarse con la administración de las cosas- el sentido de una política democrática principia a perder sentido. Porque, a fin de cuentas, si la validez de facto de las cosas tiene la última palabra ¿cuál es entonces, el espacio de la política que, desde siempre, se ha ocupado de la validez de jure de esas mismas cosas? 
La respuesta a esa pregunta quizá sea el aspecto más importante que ha de encarar el proyecto de Concertación de Partidos por la Democracia. El intento del gobierno de Bachelet -más intuitivo que sistemático- de hacer frente a ese dilema mediante el gobierno ciudadano, acabó exacerbando las expectativas y arriesgando el "mal del infinito" (Durkheim, 1977: 52). El desafio parece consistir entonces en romper la hegemonía del policy making sin incurrir en la falta de toda contención.

Para resumir todo lo anterior: el problema de la Concertación es que ha modernizado al país, pero al hacerlo, dio lugar a un tipo de público o de ciudadanía que le es dificil comprender. $\mathrm{O}$, para decirlo de otra manera: tenemos modernización pero nos sentimos incómodos con la modernidad, queremos mejorar las condiciones de vida material de los chilenos; pero esperamos se sigan comportando como masa empobrecidas e ignorantes que no piden cuentas ni reclaman; queremos democracia, pero seguimos pensando que las mayorías son masas envilecidas o alineadas por el consumo. En esas quejas hay algo también de ideológico. Después de todo, la matriz de lo ideológico regula la relación entre lo visible y lo invisible, lo imaginable y lo inimaginable, así como los cambios producidos en esa relación y, por lo mismo, es tan ideológico pretender que lo nuevo no es más que una continuación del pasado, como creer, en contra del Marx del Dieciocho Brumario, que existe la novedad absoluta. 


\section{Referencias}

Baumann, Z (2001) En busca de la política, México: FCE.

Brunner y Peña, comps. (2007) La reforma al sistema escolar. Aportes para el debate, UDP-UAI.

Correa Sutil, S. (2004) Con las riendas del poder. La derecha chilena en el siglo XX, Santiago: Sudamericana

Durkheim, E (1977) La educación moral, Buenos Aires, Losada.

Durkheim, E. (2003) El individualismo y los intelectuales, en Durkheim, Lecciones de Sociología, Buenos Aires, Miño y Dávila.

Funk, R. (ed.) (2006) El gobierno de Ricardo Lagos, La nueva vía chilena hacia el socialismo, Santiago: UDP.

Mannheim, K. (1966) Ideología y utopía, Madrid:Aguilar.

Marx, K. (2003) El Dieciocho Brumario de Luis Bonaparte, Madrid:Alianza Editorial.

Marx y Engels (1972) Correspondencia, Buenos Aires: Cartago.

Moulian, T. (2006) Fracturas, Santiago: Lom-Arcis.

Offe, Claus (1997) Towards a New Equilibrium of Citizen's Rights and Economic Resources? Meeting of OECD Education Ministers: Raising the Quality of Learning for All, pp. 81-108

Peña, C. (2003) Sobre la política y los políticos, Expansiva, En Foco, N 6.

Peña, C. (2006) Privacidad y medios, en Dossier, Revista de la Facultad de Comunicación y Letras, Santiago: UDP.

Peña, C. (2007) “Tres estudios sobre la política en Chile”, en Revista de Ciencia Política, PUC, vol 27, n 1.

Putnam, Robert D. (2002) Solo en la bolera - Colapso y resurgimiento de la comunidad norteamericana Barcelona, Galaxia Gutenberg

Putnam, Robert D. (1995) "Tuning In, Tuning Out: The Strange Disappearance of Social Capital in America", PS: Political Science and Politics,Vol. 28, № 4.

Putnam, Robert D. (1994) Para hacer que la democracia funcione, Caracas, Editorial Galac.

Taylor, Ch. (1995) “Cross-Purposes:The liberal-communitarian debate”, en: Philosophical arguments, Cambridge: Harvard 
ReVista de Sociología 21 / 2007 Chile Hoy

Facultad de Ciencias Sociales - Universidad de Chile

Thompson, J (1998) Los media y la modernidad. Una teoría de los medios de comunicación, Madrid: Paidos.

Thompson, J. (1990) Ideology and modern culture, Stanford: Stanford University Press.

Thompson, J. (2001) El escándalo político. Poder y visibilidad en los medios de comunicación, Buenos Aires: Paidós.

Tironi et al (2003) Cuánto y cómo cambiamos los chilenos. Balance de una década, censos 1992-2002, Cuadernos Bicentenario.

Weber, M. (1984) El político y el científico, Madrid:Alianza Editorial.

Žižek, S. (2005) “El espectro de la ideología”, en Žižek, comp. Ideología. Un mapa de la cuestión, México, FCE.

Žižek, S. (2006) Visión de paralaje, México: FCE. 